\title{
A Nova Economia Institucional e a Ecologia Organizacional aplicadas à heterogeneidade agrícola
}

\author{
Joice Zagna Valent ${ }^{1}$ \\ Glauco Schultz ${ }^{2}$ \\ Leonardo Xavier da Silva ${ }^{3}$
}

\begin{abstract}
Resumo: A Nova Economia Institucional e a Ecologia Organizacional são teorias que podem ajudar no entendimento da heterogeneidade agrícola brasileira. Esta diversidade é marcada por fortes desigualdades sociais e econômicas, causadas por desequilíbrios regionais, concentração produtiva em poucas atividades e fatores de produção. A Nova Economia Institucional contempla as estruturas de governança e o ambiente institucional, possibilitando o estudo das relações no meio rural. Já a Ecologia Organizacional pode explicar a existência da heterogeneidade das organizações agrícolas, destacando a sua adaptação a essa diversidade. Assim, o objetivo deste trabalho foi comparar as duas teorias expostas e as suas respectivas aplicações no estudo da heterogeneidade agrícola, por meio de pesquisa bibliográfica. Os resultados demonstram que a Nova Economia Institucional relata a heterogeneidade agrícola com mais clareza do que a Ecologia Organizacional.
\end{abstract}

Palavras-chave: Heterogeneidade. Agricultura. Ambiente Institucional. Processos Ecológicos.

\begin{abstract}
The New Institutional Economy and Organizational Ecology are theories that can help in the understanding of Brazilian agricultural heterogeneity. This diversity is marked by strong social and economic inequalities, because of regional imbalances and concentration of production in few activities and factors of production. The New Institutional Economy contemplates the structures of governance and the institutional environment, making possible the study of the relations in the rural environment. Organizational Ecology, on the other hand, can explain the heterogeneity of agricultural organizations and highlights their adaptation to this diversity. Thus, the objective of this work was to compare the two theories and their respective applications in the study of agricultural heterogeneity, through bibliographic research. The results show that the New Institutional Economics more clearly reports agricultural heterogeneity than Organizational Ecology.
\end{abstract}

Keywords: Heterogeneity. Agriculture. Institutional Environment. Ecological processes.

\footnotetext{
1 Doutoranda no Programa de Pós-Graduação em Agronegócios da UFRGS. jzvalent@gmail.com

2 Doutor em Agronegócios. Professor dos Programas de Pós-Graduação em Desenvolvimento Rural e em Agronegócios da UFRGS. glauco.schultz@ufrgs.br

3 Doutor em Economia. Professor dos Programas de Pós-Graduação em Desenvolvimento Rural e em Agronegócios da UFRGS. leonardo.xavier@ufrgs.br
} 


\section{Introdução}

A Nova Economia Institucional (doravante NEI) é estudada em dois níveis analíticos. O primeiro é referente às estruturas de governança, que contemplam as microinstituições e regulam uma transação específica. O principal autor deste nível é Oliver E. Williamson. O segundo é o ambiente institucional (ênfase deste trabalho), que contempla as macroinstituições, a base das interações entre os seres humanos e tem Douglass North como principal representante. A NEI prioriza a atitude racional nas escolhas individuais, e as origens das instituições são atribuídas à cooperação e à coordenação, ainda que essa cooperação seja alcançada para prevenir conflitos (AZEVEDO, 2000).

Para Hannan e Freeman (2005), a Teoria da Ecologia Organizacional (doravante TEO) procura explicar como os elementos políticos, sociais e econômicos afetam as organizações num dado período de tempo. Os principais autores desta teoria - Michael T. Hannan e John Freeman - apresentam um conceito importante para a TEO. O significado desse conceito traz a noção de que, tal como na biologia, as espécies carregam com elas uma constituição genética que contém as regras de transformação de energia em estrutura. Nas organizações, essa natureza genética é representada por: uma estrutura organizacional; padrões de ação e comportamento organizacional; e, uma estrutura normativa, que é a forma como as organizações são definidas e tratadas como legítimas por seus membros e pela sociedade.

Nesse contexto, considerou-se que a NEI e a TEO podem colaborar para o estudo da heterogeneidade agrícola, que é a diversidade da agricultura brasileira e compreende as diferentes formas de organização da produção, tamanhos de exploração e gestão da força de trabalho (BELIK, 2015).

Desse modo, a NEI e a TEO podem ser complementares para explicar a diversidade existente no meio rural. Existe uma relação hierárquica entre estas teorias, pois o ambiente institucional estabelece o contexto social para processos ecológicos organizacionais. Outros pontos em comum dizem respeito às escolhas dos agentes que obedecem a fatores não econômicos, como preferências e ideologias diante de um mundo permeado de incertezas (BAUM, 1998). Ainda, Simon (1970) relata que a racionalidade das pessoas é limitada. 
Para Baum (1998), o ambiente institucional enfatiza que as organizações devem estar em conformidade com seus elementos (culturais, normativos, estruturais e políticos) para serem aceitas como legítimas. A pesquisa destes elementos tem crescido consideravelmente na TEO. À medida que o ambiente institucional de uma organização muda, devido às turbulências políticas e regulamentações governamentais, a pesquisa ecológica compara taxas de fundação e fracasso entre populações organizacionais. Assim, a conjugação da NEI e da TEO potencializam a capacidade de explicação para a heterogeneidade agrícola e suas implicações no meio rural.

Diante do exposto, o presente artigo teve como objetivo comparar a NEI e a TEO e a aplicação destas teorias no estudo da heterogeneidade agrícola. A base teórica do trabalho apresenta ideias dos principais autores e de alguns estudiosos da NEI (Oliver Williamson e Douglass North) e da TEO (Michael T. Hannan e John Freeman).

Esta pesquisa foi classificada como bibliográfica, pois consiste no levantamento de referências teóricas já publicadas por meios escritos e eletrônicos, como livros, artigos científicos, páginas de web sites (FONSECA, 2002). Os exemplos mais característicos desse tipo de pesquisa são investigações sobre ideologias ou aquelas que se propõem à análise das diversas posições acerca de um problema (GIL, 2007). Este tipo de investigação é útil para integrar as informações de estudos realizadas separadamente, mas que podem apresentar resultados conflitantes e/ou coincidentes. Também podem identificar temas que necessitam de evidência, auxiliando na orientação de investigações futuras (LINDE e WILLICH, 2003).

A análise dos dados encontrados foi de natureza qualitativa. Entendeu-se ser esta maneira a mais apropriada para responder à questão formulada, a fim de chegar a considerações e reflexões que satisfaçam às expectativas da investigação.

\section{Referencial teórico}

\subsection{A Nova Economia Institucional}

A NEI estabelece as bases para a interação social, econômica e política entre as pessoas nas organizações. Ela tem dois níveis de análise: a estrutura de governança 
(microinstituições) e o ambiente institucional (macroinstituições). Esta teoria reconhece que a sociedade tenta estruturar o seu ambiente para reduzir a incerteza institucional (AZEVEDO, 2000). Para Williamson (1993), a estrutura de governança carrega os modos distintos nos quais as transações são realizadas, respectivamente, mercado, contrato e hierarquia.

Esta estrutura abrange um conjunto de regras que governam os contratos nas transações e envolve a compreensão da Economia dos Custos de Transação (ECT) com seus pressupostos comportamentais de racionalidade limitada e oportunismo. Conforme Azevedo (2000), a racionalidade limitada está relacionada à incompletude dos contratos ex ante. Por outro lado, o comportamento oportunista dos agentes leva à renegociação e, eventualmente, a disputas e rompimentos ex post.

Os atributos de transação, considerados pela ECT como influenciadores dos sistemas de governança adotados, são frequência, incerteza e especificidade dos ativos. A frequência relaciona-se com a recorrência ou regularidade da transação, ou seja, em transações recorrentes, as partes podem desenvolver reputação, o que limita seu interesse em agir de modo oportunista. O segundo atributo identifica-se com o grau de incerteza das transações, relacionado à disponibilidade de informações e ao comportamento oportunista das pessoas. Em um ambiente de incerteza, os agentes não conseguem prever os acontecimentos futuros, e, assim, o espaço para renegociação é maior. O terceiro, por sua vez, é a especificidade dos ativos, relacionada aos custos advindos da impossibilidade de alocação alternativa daquele ativo em outra transação qualquer (WILLIAMSON, 1985).

O ambiente institucional destaca o papel das macroinstituições sobre as interações econômicas entre os membros de uma mesma sociedade. Para isso, são analisados três elementos: a) regras formais; b) restrições informais; e, c) direitos de propriedade.

As regras formais são referentes à constituição, a legislações complementares e ao conjunto de políticas públicas, como, por exemplo, a defesa da concorrência, a política agrícola e a política de reforma agrária, no caso da agricultura. As restrições informais consistem em valores, tabus, costumes, religiões, códigos de ética, laços étnicos e familiares, que representam o importante papel econômico de restringir o comportamento dos agentes. Já os direitos de propriedade formam um conjunto particular de instituições que definem, limitam e garantem os direitos de propriedade (AZEVEDO, 2000). 
Uma contribuição de destaque na NEI está no fato de como os agentes percebem a estabilidade das regras pelos conflitos com as outras regras formais e, principalmente, com as restrições informais (AZEVEDO, 2000). Estas restrições são importantes na hora da tomada de decisão pelos agentes. North (1990) admite que as escolhas dos agentes também obedecem a fatores não econômicos, como o altruísmo, as preferências, a cultura, os costumes e ideologias. Estes fatores fazem parte do ambiente institucional.

Neste trabalho, é dada ênfase ao ambiente institucional, então é importante distinguir instituições de organizações. A primeira está relacionada ao conjunto de restrições formais e informais que regulam a interação humana na sociedade. $\mathrm{O}$ ambiente institucional é definido pelo conjunto das regras políticas, sociais e legais que estabelecem as bases para produção, troca e distribuição, ou seja, as próprias regras do jogo social. As organizações desenvolvem-se dentro do ambiente institucional, refletindo as estratégias dos atores, limitados pelas regras institucionais (NORTH, 1990). Para o mesmo autor, as instituições tendem a apresentar mudanças em longo prazo. Assim podem ser entendidas as mudanças culturais, os costumes e as regras que caracterizam as diferentes sociedades. As organizações que nascem dentro do ambiente institucional são limitadas e condicionadas pelas regras institucionais.

Então, para North (1990), instituições são responsáveis por diminuir as incertezas, tornando o ambiente social mais favorável para que as pessoas sejam estimuladas a tomar decisões econômicas e políticas. Desta maneira, os custos de transação nas organizações são reduzidos, e poderá ocorrer a maximização e eficiência dos mercados como símbolos de desenvolvimento.

Williamson (1993) ainda complementa, relatando que as instituições definem os limites das organizações, mas são, da mesma forma, afetadas por elas. Portanto, os parâmetros de deslocamento do equilíbrio definem os modos eficientes de governança. A figura 1 explica melhor esta situação: 


\section{Figura 1 - Relações institucionais}

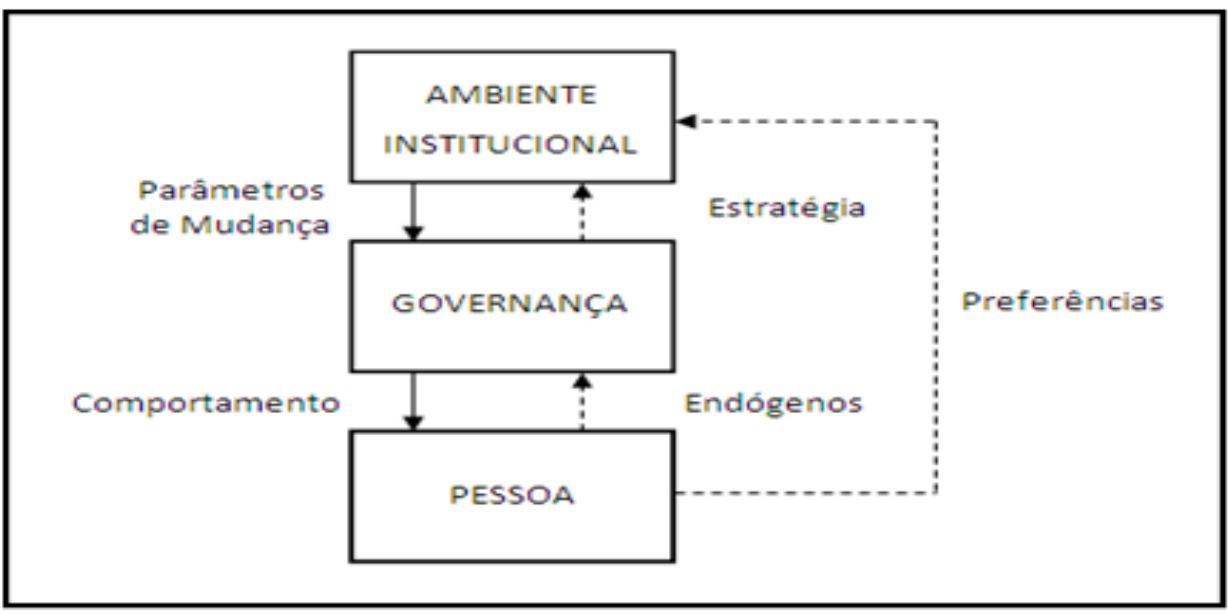

Fonte: Zylberstajn (1995), adaptado de Williamson (1993).

Um modo eficiente de governança resultará da interação entre o ambiente institucional e o comportamento das pessoas. Por outro lado, efeitos endógenos e estratégias, devem ser considerados, uma vez que as instituições limitam o comportamento das pessoas e também pelo fato de que as organizações afetam, em longo prazo, o próprio ambiente institucional. Já os parâmetros para uma mudança institucional dependem da escolha acertada de uma estrutura de governança e do comportamento (mesmo que limitado) das pessoas em uma organização (ZYLBERSTAJN, 1995).

Uma mudança nas limitações institucionais alterará os custos de negociação e dará lugar a esforços para criar, por evolução, novas convenções ou normas. Estas resolverão os novos problemas que possivelmente surgirão devido às mudanças ocorridas. Então, o processo de desenvolvimento econômico ocorre em um ambiente de evolução institucional com múltiplos equilíbrios. Os desequilíbrios podem ser parciais, e geralmente ocorrem quando refletem mudanças nos gostos ou preferências das pessoas. Há, também, a possibilidade de desequilíbrios institucionais, causados, por exemplo, por processo de mudanças institucionais descontínuas, processos de rupturas abruptas, como revoluções, desastres naturais, entre outros (ZYLBERSTAJN, 1995).

North (2006) adverte que as instituições afetam o desempenho da economia, porém a teoria econômica e sua história não mostram muito interesse em demonstrar a função das instituições no desempenho econômico. Nesse sentido, para os novos institucionalistas, o processo de desenvolvimento econômico é também um processo de desenvolvimento das 
instituições ou evolução de uma determinada matriz institucional; portanto, as instituições importam e devem ser acrescentadas aos modelos de desenvolvimento econômico.

\subsection{A Teoria da Ecologia Organizacional}

A TEO é um subcampo dos estudos organizacionais e enfatiza os processos de seleção ambiental, tendo como autores principais Michael T. Hannan e John Freeman (1977), com o artigo intitulado "The population ecology of organizations" (um dos objetos de estudo deste trabalho). Outros autores que ganharam destaque foram Aldrich e Pfeffer (1976); Aldrich (1979) e McKelvey e Aldrich (1983). A intenção desta teoria é identificar o motivo da existência de tanta diversidade de organizações e destacar a seleção natural, ocasionada pelo ambiente onde as empresas estão inseridas, e não pela adequação das organizações (BAUM, 1998). Para Hannan e Freeman (1977), o conceito de seleção, aplicado à TEO, significa que o ambiente seleciona as organizações, causando a morte ou a evolução das empresas. Esta seleção também é denominada de sistemática.

Conforme Hannan e Freeman (1977), as organizações podem desenvolver uma capacidade de adaptação, porém com desempenho limitado. A sobrevivência de uma organização adaptada às condições do meio depende da natureza do ambiente e das situações competitivas.

Neste contexto, a TEO tenta explicar a taxa de fundação e/ou fracasso de empresas. As causas do fracasso podem estar vinculadas ao acesso restrito que as novas organizações têm aos recursos disponíveis na comunidade, ou também por não terem logrado a obtenção de legitimidade. Para Rossoni (2016), a legitimidade é um elemento estrutural que leva as organizações a atuarem em estratos sociais com lógicas distintas. Como consequência, tais lógicas podem apresentar diferentes conteúdos ou fórmulas legitimadoras, que, por sua vez, também podem apresentar dimensões, níveis e origens variados de legitimidade. Então, a legitimidade media a relação entre objetos e estrutura, a partir do grau de enraizamento de tais estruturas institucionais na sociedade.

A idade mais avançada também pode ser um fator crítico para muitas organizações, por causa da inércia estrutural. Esta é uma tendência que ocorre nas organizações maiores e 
mais velhas, dificultando ações adaptativas às mudanças ambientais e institucionais. A densidade populacional é também outro aspecto analisado pelos "ecologistas organizacionais" para explicar as taxas de fundação e fracasso. O aumento da densidade pode causar a disputa por recursos disponíveis para uma população organizacional, gerando a saída do mercado daquelas que obtiveram menor legitimidade junto à comunidade (HANNAN; FREEMAN, 1977). Para tanto, a TEO utiliza três elementos de análise inicial: a) organizações; b) populações; e, c) comunidades.

Um conjunto de organizações engajadas em atividades e padrões similares constitui uma população. Por sua vez, as populações formam-se como resultado de um processo que segrega uma organização da outra, incluindo incompatibilidades tecnológicas e ações institucionais. Já as comunidades organizacionais são formadas pelas relações de populações engajadas em atividades distintas (BAUM, 1998).

Hannan e Freeman (1977) dissertam sobre dois conceitos que merecem destaque na TEO: a inércia estrutural e o processo evolucionário. $O$ primeiro conceito relata que as mudanças ocorridas nas organizações não podem ser controladas e que o gestor possui capacidade limitada. Já o processo evolucionário descreve três etapas: variação (processo planejado ou não), seleção (organizações adaptadas ao ambiente que sobrevivem) e retenção (organizações selecionadas são preservadas e reproduzidas). Aldrich (1979) e Campbell (1965) ainda incluem competição como processo evolucionário.

Dessa forma, os processos básicos são definidos por comportamentos humanos, que vão ajustando a relação das organizações com o ambiente. Portanto, os trabalhadores também são parte integrante de uma comunidade organizacional e respondem por si e pela organização (BAUM, 1998).

Para alguns estudiosos, a ação humana não interfere nas organizações, porém a TEO disserta que as pessoas influenciam o futuro organizacional. Contudo, sob condições de incerteza, existem restrições às habilidades humanas para implementar mudanças que aumentem as chances de sobrevivência e sucesso da empresa diante de um ambiente competitivo. Dessa forma, as ações das pessoas não explicam a diversidade nas populações de organizações, elas apenas influenciam a responsabilidade de controle sobre o sucesso e sobrevivência das organizações (HANNAN; FREEMAN, 1977). A TEO assume que as pessoas 
não podem prever sempre quais mudanças serão bem-sucedidas nas organizações e rápidas o suficiente para acompanhar as demandas de ambientes instáveis (BAUM, 1998).

Nessa perspectiva, são feitas as observações referentes à diversidade das organizações, às dificuldades de planejar e executar mudanças rápidas em um ambiente incerto e mutável e à frequente instabilidade das comunidades das organizações. Assim, a inércia estrutural relata que a maioria das inovações organizacionais ocorre no início da história, ou seja, na fundação das empresas, pois as organizações já existentes, geralmente, têm dificuldades para mudar estratégias de forma rápida. A mudança e a variabilidade organizacionais são o reflexo da substituição de uma organização inerte por outra. As pressões externas em direção à inércia são fortes e divididas nos seguintes fatores: barreiras legais e fiscais de entrada e saída de mercados; restrições internas sobre a disponibilidade de informações, paralelas às restrições externas; restrições de legitimidade, as quais também emanam do ambiente; e há ainda um problema de racionalidade coletiva (HANNAN; FREEMAN, 1977).

Para explicar um dos principais tópicos da TEO, a taxa de fundação e fracasso de empresas, esta teoria enfatiza causas sociais, econômicas e políticas. Estes fundamentos produzem variações nas taxas de fundação e fracasso das organizações ao longo do tempo (ALDRICH; WIEDENMAYER, 1993). Baseado nisso, as referidas taxas focalizam três temas: processos demográficos, processos ecológicos e processos ambientais.

Os processos demográficos examinam os efeitos das características das empresas sobre as taxas de fracasso em populações organizacionais. Assim, esta ênfase possibilita às organizações mais jovens terem taxas mais altas de fracasso, porque elas têm que adquirir novos conhecimentos e rotinas diferentes. Isto dificulta a obtenção da legitimidade. Hannan e Freeman (1984) sugerem que as pressões seletivas favorecem organizações capazes de demonstrar confiança e alta reprodutividade. Estas características aumentam à medida que avança a idade organizacional. Entretanto, as mudanças ambientais também criam oportunidades para que novas organizações entrem e destruam as posições competitivas daquelas já estabelecidas. Dessa maneira, Baum e Oliver (1991) relatam que as organizações jovens são capazes de obter legitimidade mais cedo, por meio da formação de vinculações institucionais à comunidade e aos agentes públicos. 
Os processos ecológicos, para Hannan e Freeman (1977), usam a teoria do tamanho do nicho de mercado, para formular um modelo de capacidades diferenciais de sobrevivência de organizações com poucos clientes potenciais (especialistas), e de organizações com tolerância adaptativa e variações mais amplas - polimorfismo - nas condições ambientais (generalistas). Portanto, cada organização, em uma população, influencia e também sofre influência pela competição.

Já os processos ambientais identificam a convergência das perspectivas ecológicas e institucionais em organizações como o desenvolvimento da pesquisa em teoria organizacional. As mudanças institucionais e a evolução tecnológica são processos ambientais que condicionam relações históricas estruturais (SINGH; LUMSDEN, 1990).

Frente ao exposto, as pressões de seleção nas sociedades modernas favorecem organizações que produzem de forma confiável, com ação coletiva, e explicam racionalmente suas atividades. Este desempenho também contribui para a inércia estrutural. Assim, a TEO favorece organizações responsáveis e confiáveis, como também organizações com altos níveis de inércia. A partir disso, considera-se que o ambiente favorece sistemas estáveis (HANNAN; FREEMAN, 1977; 1984).

\subsection{Heterogeneidade agrícola}

A agricultura brasileira é responsável pelo abastecimento de alimentos no país. Desta maneira, é necessário que haja harmonia na inter-relação existente entre as atividades que acontecem antes e dentro das propriedades rurais com aquelas que ocorrem quando os produtos são destinados ao consumo. Conforme Flores, Ries e Antunes (2006), além do lucro, o empresário rural também deve visar a que a sua propriedade cumpra o papel social e ecológico da terra.

Esse não é um papel tão fácil de cumprir, pois a heterogeneidade no meio rural brasileiro é marcada por fortes desigualdades sociais e econômicas. Belik (2015) relata que a heterogeneidade é um fenômeno comum a todas as agriculturas, porém a desigualdade é uma marca da agricultura brasileira. Schneider (2009) explica que a heterogeneidade estrutural e produtiva no setor agrícola brasileiro pode ser observada por meio da 
concentração produtiva em poucas atividades, concentração dos fatores de produção e desequilíbrios regionais. Esta heterogeneidade também implica modificações, transformações, reações e alternativas na agricultura. A busca de novas estratégias emerge a partir de estilos de agricultura, práticas agrícolas e relações sociais existentes, as quais, simultaneamente, reproduzem ou transformam o meio. Ploeg (2006) denomina a heterogeneidade observada no espaço rural como "estilos de produção". Estes estilos vão de diferentes formas de agricultura camponesa a combinações altamente complexas, como a agricultura patronal. Para o autor, uma perspectiva centrada nos atores parte do pressuposto de que diferentes agricultores (ou categorias de agricultores) definem e operacionalizam seus objetivos e práticas de gerenciamento agrícola com base em diferentes critérios, interesses, experiências e perspectivas. Isto é, os agricultores desenvolvem, ao longo do tempo, projetos e práticas específicas para a organização de sua atividade agrícola. O resultado dessas práticas reflete na heterogeneidade agrícola existente, que pode ser analisada em aglomerados de estilos específicos de agricultura.

\section{Discussão}

3.1 A Nova Economia Institucional e a heterogeneidade agrícola

O desenvolvimento agrícola é um processo multifacetado e complexo. A dinâmica agrícola ilustra os aspectos pelos quais as instituições desempenham seu papel (LONG, 2001). Assim, a heterogeneidade na agricultura deve ser analisada como práticas social, ambiental e econômica. Para entender a heterogeneidade agrícola, é preciso conhecer as regras formais e as restrições informais, e como elas estão evoluindo ao longo do tempo, pois esses fatores também determinam a heterogeneidade agrícola. Por esse motivo, a NEI exerce um papel importante no desenvolvimento agrícola. Uma questão referente a esse processo é como relacionar a heterogeneidade e as relações micro e macroinstitucionais.

Do ponto de vista microinstitucional (regras que regulam uma relação específica entre pessoas, associações, cooperativas ou empresas), o papel das instituições é especialmente importante para os sistemas agroindustriais. As estruturas de governança, 
por meio da criação de regras, disciplinam o comportamento dos agentes econômicos de um sistema agroindustrial, o que pode ser decisivo para a eficiência e competitividade no mercado. Em outras palavras, se duas empresas agrícolas forem comparadas, aquela que se ajustar mais rapidamente a uma mudança ambiental, na direção de um novo modo de governança minimizador de custos de produção e transação, poderá ser considerada mais competitiva, permitindo a sua permanência no mercado com maior eficiência (AZEVEDO, 2000; ZYLBERZTAJN, 1995). Esse ambiente microinstitucional pode pensar em políticas públicas que ofereçam as mesmas condições econômicas, institucionais, tecnológicas e ecológicas para todos os agricultores. Assim, o meio rural tornar-se-ia mais homogêneo, com as mesmas oportunidades para todos os trabalhadores rurais. Enquanto essas condições não forem acessíveis para todos os agricultores, alguns desenvolvem projetos e práticas específicas para a organização de sua atividade agrícola, o que também reflete na heterogeneidade agrícola. Belik (2015) reforça que o acesso restrito aos fatores de produção e o foco nas capacidades deveriam ser objeto de programas públicos para transformar a realidade do meio rural brasileiro.

Já do ponto de vista macroinstitucional, existem argumentos relacionando a garantia de direitos de propriedade a outros elementos de eficiência econômica, como o nível de investimentos. As macroinstituições compõem o ambiente institucional sobre as interações econômicas entre os membros de uma mesma sociedade (AZEVEDO, 2000). O ambiente institucional interfere na forma de governança eficiente, devido às normas formais, às restrições informais e ao direito da propriedade.

$\mathrm{Na}$ heterogeneidade agrícola, novas práticas são apresentadas e legitimadas. A produção orgânica de alimentos é um exemplo desta heterogeneidade, porque se mostra como uma alternativa para modificações de práticas produtivas. Assim, novas estratégias surgem a partir de uma prática agrícola sustentável. Novas relações sociais se formam, diminuindo a desigualdade no meio agrícola. Para North (2006), dessa forma, novas organizações (jogadores) surgem com pessoas dedicadas à determinada atividade e com o objetivo de tornarem-se legítimas na comunidade. O ambiente institucional é que determina se este objetivo será alcançado, principalmente por causa do relacionamento com a 
comunidade, do comportamento, dos códigos de conduta, da valorização da cultura local, entre outros.

Portanto, as limitações institucionais definem os tipos de organizações que serão criadas e a sobrevivência destas em um ambiente competitivo e em constante mudança. North (2006) relata que as instituições, aliadas à tecnologia empregada, também afetam os custos de transação e podem transformar os meios produtivos. Williamsom (1985) relata que os atributos (frequência, incerteza e especificidade dos ativos) das estruturas de governança também se modificam, conforme as mudanças institucionais.

A NEI prioriza a atitude racional nas escolhas individuais, e as origens das instituições são atribuídas à cooperação e à coordenação. Essa cooperação pode reduzir as desigualdades causadas pelo acesso diferenciado aos fatores de produção (em especial à tecnologia). Essas tranformações podem resultar em maior diversidade no meio rural e no equilíbrio regional.

\subsection{A Teoria da Ecologia Organizacional e a heterogeneidade agrícola}

O setor agrícola é afetado por diversas mudanças tecnológicas. Os consumidores também vêm mudando os seus hábitos de modo muito rápido por causa de preocupações com segurança alimentar e preservação ambiental. Estas alterações fazem com que o mercado também sofra constantes mudanças. Neste contexto, muitas organizações surgem, outras fracassam, e ainda há aquelas que tentam se adaptar ao ambiente. Conforme Hannan e Freeman (1977), as organizações podem desenvolver uma capacidade de adaptação, porém com desempenho limitado.

O aumento das populações organizacionais também pode causar a disputa por recursos disponíveis, gerando a saída daquelas que obtiverem menor legitimidade junto à comunidade. Dessa forma, há a presença da heterogeneidade, pois algumas organizações não têm acesso às mesmas condições institucionais e tecnológicas do que outras. Assim, sob condições de incerteza, a adaptabilidade do setor agrícola pode ser vista como resultante do ambiente organizacional (que é dinâmico) onde os produtores estão inseridos. Estes produtores moldam os padrões do desenvolvimento agrícola. 
Dois conceitos citados por Hannan e Freeman (1977) também podem ser relacionados com a heterogeneidade agrícola: a inércia estrutural e o processo evolucionário. O primeiro conceito relata que as organizações frequentemente têm dificuldades para mudar suas estratégias conforme as rápidas mutações ambientais. Estas dificuldades para a mudança podem ser em virtude do acesso restrito à tecnologia e políticas públicas específicas, o que demonstra heterogeneidade estrutural no setor agrícola brasileiro, podendo também ser observada por meio da concentração produtiva em poucas atividades. Devido às diferentes condições institucionais, ambientais e tecnológicas, as empresas rurais devem mudar estratégias, renovar projetos e adequar seus meios produtivos para combater a desigualdade gerada por determinados ambientes heterogêneos no meio rural. Já pelo processo evolucionário, relata as condições de mudanças (variações), a adaptabilidade das organizações ao ambiente (seleção), a preservação das organizações aptas (retenção) e a competição entre as populações organizacionais. Nessa situação, a heterogeneidade pode estar presente em todos os processos, pois demonstra diversos arranjos produtivos para combater as desigualdades sociais e econômicas. Por exemplo, a produção de alimento agroecológico pode ser uma mudança que se adapta às exigências do ambiente, fazendo com que determinada empresa rural preserve-se no mercado competitivo.

Hannan e Freeman (1977) explicam que mudança e variabilidade organizacionais são reflexos da substituição de uma organização inerte por outra. Muitas vezes, a heterogeneidade institucional direciona à inércia, devido às restrições internas e externas. Pelo fato de não terem acesso ao mesmo ambiente institucional e tecnológico que grandes empresários rurais têm, por vezes, algumas propriedades agrícolas familiares tornam-se inertes e com pouca legitimidade.

Para explicar o fio condutor do discurso da TEO - a taxa de fundação e fracasso de empresas no mercado -, seus autores enfatizam causas sociais, econômicas e políticas. Tomando este pressuposto como base, as referidas taxas focalizam três temas: processos demográficos, processos ecológicos e processos ambientais. Sob a égide da heterogeneidade, todos os processos referenciados possuem influência nos "estilos 
produtivos" explicados por Ploeg (2006), modificando o modelo geral de ecologia organizacional.

\section{Considerações finais}

A NEl, em conjunto com seus níveis de análise (estruturas de governança e o ambiente institucional), contribui para o entendimento da heterogeneidade agrícola. Diferentes estruturas de governança, com custos de transação altos ou baixos, juntamente com o ambiente institucional, podem definir transformações agrícolas, alterando o ambiente. Estas mudanças podem aumentar, ou diminuir a desigualdade social e econômica, visto que a produção agrícola está inserida em um ambiente de diversidade, onde os interrelacionamentos e interdependências são cada vez mais complexos.

A TEO, por selecionar as organizações mais adaptadas ao ambiente, a princípio, exclui aquelas que não têm acesso às tecnologias e políticas públicas adequadas para a concorrência no mercado; neste caso, os agricultores familiares podem ser citados como exemplo, porém estes produtores rurais, muitas vezes, minimizam os riscos da exclusão do mercado operacionalizando novas práticas agrícolas, baseadas em diferentes critérios e experiências.

As similaridades entre a NEI e a TEO são as seguintes: os processos ecológicos organizacionais acontecem nas relações do ambiente institucional, pois os agentes obedecem a fatores não econômicos, como preferências e ideologias. Ou seja, os valores que os produtores rurais possuem determinarão se uma empresa agrícola será inerte ou não, bem como será o processo evolucionário. A racionalidade é limitada, pois depende da quantidade de conhecimento e de informação disponíveis para os agentes.

Nesse contexto, as diferentes condições institucionais, ambientais e tecnológicas são responsáveis por um ambiente heterogêneo desfavorável, gerando desigualdade social e econômica. Este mesmo ambiente instável, porém, cria condições para os agricultores diversificarem em suas propriedades. Assim, eles também se tornam heterogêneos para se adaptar às diferenças e diminuir as desigualdades rurais. Esta heterogeneidade, para Long (2001), é uma forma de desenvolvimento rural. 


\section{Referências}

ALDRICH, H. E.; PFEFFER, J. Environments of Organizations. Annual Review of Sociology, n. 2, p. 79-105, 1976.

ALDRICH, H. E. Organizations and environments. Englewood-Cliffs: Prentice Hall, 1979.

ALDRICH, H. E.; WIEDENMAYER, G. From traits to rates: An ecological perspective on organizational foundings. Advances in Entrepreneurship, Firm Emergence, and Growth, n. 1, p. 145-195, 1993.

AZEVEDO, P. F. NOVA ECONOMIA INSTITUCIONAL: referencial geral e aplicações para a agricultura. Agric. São Paulo, n. 47, p. 33-52, 2000.

BAUM, J. A. C. Ecologia Organizacional. In: CLEGG, S. R.; HARDY, C.; NORD, W. R. Handbook de estudos organizacionais: Modelos de Análise e Novas Questões em Estudos Organizacionais. São Paulo: Atlas, 1998.

BAUM, J. A. C.; OLIVER, C. Institutional linkages and organizational mortality. Administrative Science Quarterly, n. 36, p. 187-218, 1991.

BELIK, Walter. A Heterogeneidade e suas Implicações para as Políticas Públicas no Rural Brasileiro. Revista de Economia e Sociologia Rural-RESR, Piracicaba, v. 53, n. 1, p. 9-30, 2015.

CAMPBELL, D. T. Variation and selective retention in sociocultural evolution. In: BARRINGER, H. R., BLANKSTEN, G. I., MACK, R. W. (Eds.), Social change in developing areas: A reinterpretation of evolutionary theory. Cambridge: Schenkman, 1965. p. 19-48.

FLORES, A. W.; RIES, L. R.; ANTUNES, L. M. Gestão Rural. Porto Alegre: Editora dos Autores, 2006.

FONSECA, J. J. S. Metodologia da pesquisa científica. Fortaleza: UEC, 2002.

GIL, A. C. Como elaborar projetos de pesquisa. 4. ed. São Paulo: Atlas, 2007.

HANNAN, Michael T.; FREEMAN, John H. The population ecology of organizations. American Journal of Sociology, n. 82, v. 5, p. 929-964, 1977.

; St_. Structural inertia and Organizational change. American Sociological Review, n. 49 , v. 2, p. 149-164, 1984.

Empresas, v. 45, n. 3, 2005. 
LINDE, K.; WILLICH, S. N. How objective are systematic reviews? Differences between reviews on complementary medicine. J R Soc Med. n. 96, p. 17-22, 2003.

LONG, N. Development Sociology: actor perspectives. London: Routledge, 2001.

McKELVEY, B., ALDRICH, H. Populations, natural selection and applied organizational science. Administrative Science Quarterly, v. 28, p. 101-128, 1983.

NORTH, D. C. Institutions, Institutional Change and Economic Performance. Cambridge, University Press, p. 152, 1990.

NORTH, D. C. Custos de Transação, Instituições e Desempenho Econômico. 3. ed. Rio de Janeiro: Instituto Liberal, 2006.

PLOEG, J. D. O modo de produção camponês revisitado. In: SCHNEIDER, S. (Ed.). A diversidade da agricultura familiar. Porto Alegre: UFRGS, 2006. p.13-54.

ROSSONI, Luciano. O que é legitimidade organizacional? Organizações \& Sociedade - O\&S, Salvador, v. 23, n. 76, p. 110-129, 2016.

SCHNEIDER, Sergio. Ciências sociais, ruralidade e territórios: em busca de novas referências para pensar o desenvolvimento. Campo e Território, Uberlândia, v. 4, n. 7, p. 24-62, fev. 2009.

SIMON, Herbert Alexander. Comportamento Administrativo: Estudos dos Processos Decisórios nas Organizações Administrativas. Rio de Janeiro: FGV, 1970.

SINGH, J. V.; LUMSDEN, C. J. Theory and research in organizational ecology. Annual Review of Sociology, n. 16. p. 161-195, 1990.

WILLIAMSON, Oliver E. The economic institutions of capitalism. London: Free Press, 1985.

WILLIAMSON, Oliver E. Transaction Cost Economics and Organization Theory, Journal of Industrial and Corporate Change, n. 2, p. 107-156, 1993.

ZYLBERSZTAJN, Decio. Estruturas de Governança e Coordenação do Agribusiness: uma plicação da Nova Economia das Instituições. 1995. 239 f. Tese (Tese de Livre Docência em Administração - Faculdade de Economia, Administração e Contabilidade) - Universidade de São Paulo, São Paulo, 1995. 